Article

\title{
New Approach Studying Interactions Regarding Trade-Off between Beef Performances and Meat Qualities
}

\author{
Alexandre Conanec ${ }^{1,2,3}{ }^{(0)}$, Brigitte Picard ${ }^{1}$, Denis Durand ${ }^{1}$, Gonzalo Cantalapiedra-Hijar ${ }^{1}{ }^{(0)}$, \\ Marie Chavent ${ }^{2,3}$, Christophe Denoyelle ${ }^{4}$, Dominique Gruffat ${ }^{1}$, Jérôme Normand ${ }^{4}$ (D), \\ Jérôme Saracco ${ }^{2,5}$ and Marie-Pierre Ellies-Oury ${ }^{1, *}$ \\ 1 Universite Clermont Auvergne, INRA, VetAgro Sup, UMR Herbivores, F-63122 Saint-Genes-Champanelle, \\ France; alexandre.conanec@agro-bordeaux.fr (A.C.); brigitte.picard@inra.fr (B.P.); \\ denis.durand@inra.fr (D.D.); gonzalo.cantalapiedra@inra.fr (G.C.-H.); dominique.gruffat@inra.fr (D.G.) \\ 2 Contrôle de Qualité et Fiabilité Dynamique (CQFD) team, Inria BSO, F-33400 Talence, France; \\ marie.chavent@math.u-bordeaux.fr (M.C.); jerome.saracco@math.u-bordeaux.fr (J.S.) \\ 3 Universite de Bordeaux, IMB, UMR 5251, F-33400 Talence, France \\ 4 Institut de l'Elevage, Service Qualite des Carcasses et des Viandes, 69007 Lyon, France; \\ christophe.denoyelle@idele.fr (C.D.); jerome.normand@idele.fr (J.N.) \\ 5 ENSC Bordeaux INP, IMB, UMR 5251, F-33400 Talence, France \\ * Correspondence: marie-pierre.ellies@inra.fr; Tel.: +33-5-57-35-38-70
}

Received: 2 May 2019; Accepted: 4 June 2019; Published: 7 June 2019

\begin{abstract}
The beef cattle industry is facing multiple problems, from the unequal distribution of added value to the poor matching of its product with fast-changing demand. Therefore, the aim of this study was to examine the interactions between the main variables, evaluating the nutritional and organoleptic properties of meat and cattle performances, including carcass properties, to assess a new method of managing the trade-off between these four performance goals. For this purpose, each variable evaluating the parameters of interest has been statistically modeled and based on data collected on 30 Blonde d'Aquitaine heifers. The variables were obtained after a statistical pre-treatment (clustering of variables) to reduce the redundancy of the 62 initial variables. The sensitivity analysis evaluated the importance of each independent variable in the models, and a graphical approach completed the analysis of the relationships between the variables. Then, the models were used to generate virtual animals and study the relationships between the nutritional and organoleptic quality. No apparent link between the nutritional and organoleptic properties of meat $(r=-0.17)$ was established, indicating that no important trade-off between these two qualities was needed. The 30 best and worst profiles were selected based on nutritional and organoleptic expectations set by a group of experts from the INRA (French National Institute for Agricultural Research) and Institut de l'Elevage (French Livestock Institute). The comparison between the two extreme profiles showed that heavier and fatter carcasses led to low nutritional and organoleptic quality.
\end{abstract}

Keywords: trade-off; meat quality; beef performances; modeling

\section{Introduction}

The meat sector is facing various challenges in France, due to a current context of high quality demand and competiveness. Indeed, consumers expect homogeneous organoleptic quality, and more recently, consumers' expectations in terms of healthiness and the nutritional quality of food are increasing. The beef sector is obviously concerned, due to the lower meat consumption in the past few years [1]. In addition, farmers and retailers are facing low margins in a competitive sector. 
Therefore, to preserve the beef cattle industry in the territory, the sustainability of these main actors has to be enhanced by rearing more efficient animals to decrease the cost of production and provide standardized carcasses of high quality. Despite the stakes, few studies have been carried out to tackle the problem as a whole, describing the relation between these four parameters of interest: animal performances, carcass properties, nutritional qualities, and organoleptic qualities. Among these studies, a creative approach proceeding to a double dimension reduction (via a clustering of variables followed by a principal component analysis) on a dataset made of multiple variables measuring carcass value, fatty acid profile, and sensory tasting descriptors concluded that there is no relationship between the nutritional and sensory quality of the meat produced by young bulls [2]. Furthermore, other studies have highlighted some correlations (positive and negative) between these two qualities. For instance, it has been reported that a high amount of intramuscular fat enhances the flavor, the juiciness, and the tenderness of the meat [3,4], but reduces the proportion of polyunsaturated fatty acid (PUFA), whereas saturated (SFA) and monounsaturated fatty acids (MUFA) proportions increase [5]. The first objective of the present work was to integrate these four parameters of interest to analyze the relationships between them. A second aim was to set up a method of managing the trade-off to help the beef cattle industry design specifications that take the possible interaction between the nutritional and organoleptic qualities of the meat into account.

\section{Materials and Methods}

The whole method is based on a dataset of 30 animals, which will be described further. First, 62 variables measured on those animals were pre-treated to reduce the redundancy between them and keep the best indicators to evaluate the parameters of interest. From the output variables of this pre-treatment, as many models as variables were created to explain each variable by the other ones. Then, those models were evaluated with statistical tools, and the relationships that were observed with these models were compared to the two-by-two relationships described in the literature. After evaluating the modeling part, models were used to create a virtual population of animals to study the relationships between the modeled variables with more accuracy. To compare the nutritional and sensory quality of the meat, a set of importance weights was proposed to aggregate the variables evaluating those qualities and create a synthetic index for each parameter. The correlation between both of those indexes was calculated to study their relation. Finally, the 30 best and worst profiles (based on an objective of balance between nutritional and organoleptic quality) were studied to compare their main trait differences.

\subsection{Data}

\subsubsection{Animals}

Data were collected in a research project named "Lipivimus" (ANR-06-PNRA-018) investigating the effects of several lipids sources in the animal feeding on the nutritional and organoleptic qualities of the meat. Experimental procedures and animal-holding facilities respected French animal protection legislation, including the licensing of experimenters. They were controlled and approved by the French Veterinary Services (the abattoir and cattle experimental facilities license numbers were \#63 34501 and \#63 345 17, respectively). A total of 30 Blonde d'Aquitaine heifers, which were homogeneous in terms of initial age $(28 \pm 1.3$ months), live weight $(540 \pm 13 \mathrm{~kg})$, and body condition score $(2.2 \pm 0.05)$ were raised during a finishing period of 100 days. Animals were assigned at random to one of the four rations that were i) isoenergetic on a net energy basis at a level of $1.71 \mathrm{Mcal}$ of net energy/kg dry matter (DM) and ii) isonitrogenous on a metabolizable protein basis expressed in Protein Digestible in the small Intestine (PDI) units (defined by the French National Institute for Agricultural Research, or INRA, tables [6]). A lipid treatment (40 g/ $\mathrm{kg} \mathrm{DM})$ was added to the basal diet made of molasses straw $(30 \%)$ and concentrate $(70 \%)$. The control group $(n=8)$ received the basal diet without any lipid source supplements, the flaxseed group $(n=8)$ received the basal diet added with extruded flaxseed, 
the rapeseed group $(n=6)$ received a mixture composed of extruded flaxseed $(1 / 3)$ and rapeseed $(2 / 3)$, and the palmitostearate group $(n=8)$ received palmitostearate. Two of the eight initial heifers of the rapeseed diet group are missing in the database: one for health problems was removed from the group, and the other one had not been tasted by the panel of degustation; thus, numerous data were missing for this animal. Average daily gain (ADG) was calculated based on the difference between the end and the beginning weights of the fattening period. The dry matter intake was measured daily for each pen to calculate the feed conversion ration per pen (FCR), based on a mean ADG of the animals of each pen.

\subsubsection{Animal Slaughtering Process}

Animals were slaughtered at the slaughterhouse of the Société Vitréenne d'Abattage (SVA) in Vitré, France, at the mean live weight of $693 \mathrm{~kg}( \pm 10 \mathrm{~kg})$, with a body fat score of three $( \pm 0.1)$ on a scale varying from one (very lean) to five (very fat). Overall, average daily gain was $1528 \mathrm{~g} /$ day $( \pm 53 \mathrm{~g} /$ day) for the 100 day-finishing period with no significant variations between diets. Slaughtering was performed in compliance with French welfare regulations. The carcasses were not electrically stimulated, and they were chilled and stored at $4{ }^{\circ} \mathrm{C}$ until $24 \mathrm{~h}$ post mortem. Ultimate $\mathrm{pH}$ was recorded between the sixth and seventh rib using a $\mathrm{pH}$ meter equipped with a glass electrode at $24 \mathrm{~h}$ post mortem. Cold carcass weight, fat score, and conformation were measured at slaughter based on the EUROP grading system [7]. The fat, muscle, and bone proportions were estimated from the regression equations base on the dissection of the sixth rib [8]. Various fat tissues (kidney fat, pelvic fat, trimming fat) were also weighed. Professional experts from the Institut de l'Elevage scored each carcass for the intermuscular and intramuscular fat developments of the Longissimus thoracis muscle (LT) on two scales varying either from zero (absence of intermuscular fat) to five (strong intermuscular fat) based on an Institut de l'Elevage grading system, or from three (no intramuscular fat visible) to 12 (high intramuscular fat) [9], respectively. Meat color was monitored at the slaughterhouse on the LT muscle, at the sixth rib level twice, with a visual evaluation based on an Institut de l'Elevage grade varying from 1 (meat very light) to 4 (meat very dark) and using a portable colorimeter (CR400 MINOLTA) and $\mathrm{D}_{65}$ as the illuminant, because it closely approximates daylight [10]. Color coordinates were calculated in the CIELAB system [11]: $L^{*}$ (lightness), $a^{*}$ (redness) and $b^{*}$ (yellowness). The chroma (as $\left.C^{*}=\left(a^{* 2}+b^{* 2}\right)^{1 / 2}\right)$ and hue angle $\left(h^{*}=\arctan \left(b^{*} / a^{*}\right)\right)$ were also calculated. Measurements were taken at three locations on each steak and averaged.

\subsubsection{Nutritional Quality Measurement}

Samples of LT muscles (100-120 g) were collected one day post mortem at the level of the 9th and 10th ribs, cut into small pieces, frozen in liquid $\mathrm{N}_{2}$, and stored at $-80^{\circ} \mathrm{C}$. Just before analysis, the frozen samples were mixed in liquid $\mathrm{N}_{2}$ in an analytical mill (modelM-20, IKA-Werke, Stouten, Germany) to obtain fine powder. Muscle lipids and fatty acids were extracted and quantified as previously described by Habeanu et al. [12]. Briefly, total lipids were extracted according to the method of Folch et al. [13] by mixing the LT muscle powder with a 2/1 chloroform/methanol mixture $(v / v)$ and quantified by gravimetry. Fatty acid extraction and transmethylation into fatty acid methyl esters (FAME) were subsequently performed according the methods of Bauchart et al. [14]. Fatty acid methyl ester analysis was performed with gas liquid chromatography using a Peri 2100-chromatography system (Perichrom Society, Saulx-les-Chartreux, France) fitted with a CP-Sil 88 glass capillary column (Varian, Palo Alto, CA, USA; length $=100 \mathrm{~m}$; diameter $=0.25 \mathrm{~mm}$ ). The carrier gas $\mathrm{was}_{2}$, and the oven and flame ionization detector temperatures described by Scislowski et al. [15] were used. Total fatty acid (FA) was quantified using C19:0 as an internal standard. The identification of each individual FAME and the calculation of the response coefficients for each individual FAME were performed using the quantitative mix C4-C24 Fame (Supelco, Bellafonte, PA, USA). 


\subsubsection{Organoleptic Quality Measurement}

At $48 \mathrm{~h}$ post mortem, the Longissimus thoracis muscle samples that were used for organoleptic evaluation were removed from carcasses $\left(7^{\mathrm{e}}\right.$ and $\left.8^{\mathrm{e}} \mathrm{rib}\right)$, placed in sealed plastic bags under vacuum, and kept at $4{ }^{\circ} \mathrm{C}$ without light for aging for 10 days. Then, each sample was frozen and stored at $-20^{\circ} \mathrm{C}$ awaiting organoleptic evaluation. Samples were thawed, without stacking or overlapping, for $24 \mathrm{~h}$ before cooking and organoleptic assessment. Then, they were cut into mini-roasts (50-g cubes, $4 \mathrm{~cm}$ thick). Each mini-roast was baked (thermolyne muffle furnace, Model 6000, Bioblock Scientific, Illkirch Graffenstaden, France) without dressing. There were heated to $310^{\circ} \mathrm{C}$ for seven minutes, and cut into four bites that were immediately served in another porcelain plate to 12 trained panelists. The panelists rated the sample on a 10-cm unstructured line scale (from 0 to 100) measured in $\mathrm{mm}$ for the following texture attributes: global tenderness defined as the ease of chewing the sample between teeth: from extremely tough (0) to extremely tender (100), juiciness defined as the amount of moisture released in the mouth: from extremely dry (0) to extremely juicy (100), and global intensity of flavor from low intensity (0) to very high intensity (100). Height descriptors of flavor were also used, from low intensity (0) to very high intensity (100): sweet flavor, acid flavor, bitter flavor, fatty flavor, metallic flavor, rancid flavor, fish flavor, and blood flavor. The sessions were carried out in a room equipped with individual booths under artificial red light to reduce the influence of the appearance of the samples. At each session, a monadic presentation of a maximum of 12 samples was done, with each sample being selected in random order.

\subsection{Modelization}

\subsubsection{Pre-Treatment of the Variables}

This experiment resulted in the collection of 62 variables (described in Appendix A), which were centered and reduced by the standard deviation. The variables were classified into one of the four parameters of interest (i.e., animal performances, carcass properties, nutritional quality, and organoleptic quality of meat). Then, a clustering of the variables was performed with the variables evaluating each parameter to reduce the redundancy among the variables and only keep a small set of indicators to evaluate those parameters. Clusters of correlated variables were formed with this statistical tool [16], and a criteria was calculated to evaluate the cohesiveness of those clusters (the closer the criteria was to $100 \%$, the more correlated the variables that were gathered into each clusters were to each other). Then, the authors decided to resume the clusters by either a linear combination of the variables of the cluster (first component of the principal component analysis (PCA) on the variables of the cluster) or by one of the variables from the cluster. These choices are assumed to be subjective, but were based on the literature and the main indicators that were used to describe the carcass traits [17], the nutritional quality [18-20], and the organoleptic quality [21].

\subsubsection{Variable Relations Modeling}

To study the relations between the four parameters of interest, each variable was modeled with the set of all the variables that were evaluating another parameter of interest other than the one that the variable was to model. To clear the notation, let's define $\mathrm{M}_{\mathrm{var}}$ to denote the model built to explain the dependent variable var.

To determine the most relevant model as possible, several types of regression models (linear model $(\mathrm{lm})$, random forest (rf), sliced inverse regression (sir), ridge regression, and partial least square regression (plsr)) were compared using modvarsel $\mathrm{R}$ package [22]. The underlying methodology used in this package is entirely computational, generating a training sample several times $(n=50)$, to build models that were then evaluated with a mean square error (MSE) criteria calculated on the corresponding test dataset sample. This package also provides a tool to measure the importance of each independent variable in the corresponding regression model, and then select the best ones to build the most accurate model. The quality of the model was evaluated with the adjusted coefficient 
of determination (adjusted coefficient of determination (adj $\left.R^{2}\right)$ is a $R^{2}$ penalized by the number of independent variables into the model) calculated twice: first on the training data, which were used to build the model, and then a second time with a method developed by Harrell et al. [23] based on bootstrap resampling $(B=100)$ to evaluate without overfitting the accuracy of the model. The combination of both methods enables estimating model overfitting.

\subsubsection{Study of the Relationships Modeled}

Two strategies were set up to analyze the relationships between the dependent variable and the independent variables. As mixed parametric and non-parametric models complicate the quantification of the importance of each independent variable in the prediction models, a common method was used to evaluate this importance, mobilizing the decomposition of the variance [24] in the sensitivity $\mathrm{R}$ package [25] by calculating a sensitivity index $(\mathrm{Si} \in[0,1])$. A sensitivity index was assigned to each indicator into the model: the most influential ones were associated with a value close to one and the less influential was assigned a value close to zero. The second strategy to analyze the model behavior was to visualize the variations of the model predictions where all the (centered and reduced) independent variables were set to their mean zero, except for one that was taking a range of values in $0 \pm 2 \sigma$ (i.e., $[-2,2]$ as $\sigma=1$ ). This procedure was repeated as many times as the number of independent variables of the model.

\subsection{Trade-Offs Methodology}

\subsubsection{Aggregation of the Variable Evaluating the Parameters of Interest}

Several variables were used to evaluate each parameter of interest. Therefore, to compare the nutritional and organoleptic quality, a synthetic index was created for both. Those indexes were calculated by a linear combination of the variables evaluating the parameters of interest weighted by their importance. The importance weights (Table 1) were proposed by a set of experts from the INRA (French National Institute for Agricultural Research) and Institut de l'Elevage (French Livestock Institute) based on their knowledge and the literature. For organoleptic quality, the weights were mainly based on the Meat Quality 4 (MQ4) [21] but for the nutritional quality, even if there are some considerations about the studied indicators in the literature, no objective equation has been created so far [18-20].

Table 1. Importance weights related to each variable evaluating the nutritional and organoleptic qualities.

\begin{tabular}{cccc}
\hline Parameter of Interest NQ & Weights & Parameter of Interest OQ & Weights \\
\hline lipid content & -0.15 & tenderness & +0.425 \\
long FA & +0.05 & juiciness & +0.150 \\
C16:0/C18:0 ratio & -0.15 & flavor intensity & +0.175 \\
$n-6 / n-3$ ratio & -0.25 & bitter flavor & -0.025 \\
PUFA/MUFA ratio & +0.25 & rancid and fish flavors & -0.125 \\
CLA & 0.1 & fatty vs. metal & -0.050 \\
trans FA & -0.05 & blood and acid flavors & -0.050 \\
Total (in absolute value) & 1 & Total (in absolute value) & 1 \\
\hline
\end{tabular}

CLA: conjugated linoleic acids, FA: fatty acid, MUFA: monounsaturated fatty acids, PUFA: polyunsaturated fatty acid, NQ: nutritional quality, OQ: organoleptic quality.

\subsubsection{Generation of Virtual Animals}

Facing a low number of animals, the models of prediction were used to create virtual animals $(n=500)$. The aim of this approach was to study the interactions between the parameters of interest based on the models and not the real animals (which have only been used to create the models). However, it was assumed that the virtual animals were built to be realistic (i.e., those animals could be real), even if the bias of the models has to be taken into account. 
The (simplified) algorithm to generate virtual animals is given in Appendix B. First, one of the parameters of interest was chosen to set the value of its variables. Each variable could vary from -2 to $2(0 \pm 2 \sigma)$ with a step of 0.1 . To prevent unrealistic combinations of the variables from that chosen parameter of interest, simple linear regressions were computed between these variables. A confidence interval at $95 \%$ based on those regression were decided if the combination were realistic or not. Then, all the variables that were not in the chosen parameter of interest were estimated through the prediction models. Since the models were dependent all together and the estimation of the variables made successively, all the estimation were initially set to 0 . The estimations of all the variables were made several times $(n=10)$, with an order of the estimation randomly assigned, to converge to a stable state.

\subsubsection{Statistical Analysis}

After their generation, the virtual animals were aggregated following the procedure described in Section 2.3.1. The correlation between the two synthetic indexes was computed to evaluate the link between the nutritional and the organoleptic qualities.

The trade-off method consisted of picking the best animal based on its performances regarding both of the qualities studied. To determine the best animals, a targeted point was set, and the 30 closest animals to this point were selected. The targeted point was set at the coordinate $(\mathrm{NQ}=2, \mathrm{OQ}=2)$ corresponding to two standard deviations of the synthetic indexes (which means that only a few animals would reach such performances). The same procedure was applied to select the 30 worst animals close to the opposite targeted point $(\mathrm{NQ}=-2, \mathrm{OQ}=-2)$.

Then, the best and worst selected virtual animals were analyzed. The distribution of their traits was compared by using the Wilcoxon test (robust non-parametric test which does not need to verify the normality assumption) on each variable.

\section{Results}

\subsection{Pre-Treatment of the Variables}

The selection of the relevant variables evaluating the parameters of interest are explained in this section. The cluster affectation of each variable's information and the correlation with the linear combination of all the variables of the cluster are given in Appendix A. A clustering of variables was performed for each parameter of interest, except for Animal Performances (APs) since the (only) three variables evaluating this parameter were uncorrelated.

For Carcass Properties (CP), six clusters were created, which had good cohesiveness $(63.7 \%)$. Intermuscular fat score and carcass fat development were associated in the same cluster, whereas the amount of the different fats (such as abdominal, fifth quarter, etc.) were all associated in another cluster. Thus, intermuscular fat appears to be only weakly linked to removed fat. This distribution of fat variables is consistent with results of Yang et al. [26], who indicated that intermuscular fat is independent from the other fat deposits. Therefore, two linear combinations were chosen to represent these two clusters (Table 2). Logically, the color variables of $a^{*}, b^{*}$, and $C^{*}$ were positively linked, confirming the correlations already established by Mancini and Hunt [27]. The clustering of $h^{*}$ and $L^{*}$ color variables with fat proportion might be explained by the impact of fat on muscle color perception. Two linear combinations were also computed to represent both of these color aspects. Let us also mention that cluster CP1 was gathering carcass weight and bone proportion (logically negatively correlated) and $\mathrm{pH}$. Since $\mathrm{pH}$ is an important indicator for the meat quality, it was proposed to separate the $\mathrm{pH}$ from the two other variables, which were informing more on the carcass weight. Finally, to summarize this cluster, $\mathrm{pH}$ and the carcass weight variables were kept as output variables of the pre-treatment operation.

The Nutritional Quality (NQ) of the meat was evaluated by 28 variables: the lipid content and 27 fatty acid measures or the ratio/sum of them. Therefore, the decision was made to withdraw the lipid content from the analysis (because the information of this indicator is also important to compare 
with intramuscular fat, for example), and perform the clustering of variables only on the fatty acid variables. The cohesiveness of the six clusters was higher than that for CP (around 72\%). Two clusters were not explicitly clear. The NQ3 cluster regrouped variables describing the opposition between $n-3$ and $n-6$ fatty acids. The presence of SFA and C16:0 in this cluster could be explained by a link between the low amount of $n-3$ in proportion when SFA (mainly C16:0) is high. For this cluster, it was proposed to take the $n-6 / n-3$ ratio, which is a strong nutritional indicator, into the ANSES recommendations [28]. The NQ4 cluster was also not clear, but on the whole, it appeared to be describing the opposition between MUFA and PUFA. For this cluster, the linear combination of the variable was taken and renamed as the ratio PUFA/MUFA.

Organoleptic Quality (OQ) is usually described in the literature with three main indicators: tenderness, juiciness, and flavor. The sensory variables available in this experiment gave a larger analysis of the flavor aspect. Therefore, the clustering of variables was performed only with these variables. Five clusters were formed with a cohesiveness equal to $63.6 \%$. The synthetic index that was chosen was strongly correlated with the input variables, meaning that a small amount of information was lost in the dimension reduction step.

Table 2. Output variables of the pre-treatment operation describing the four parameters of interest (PI).

\begin{tabular}{|c|c|c|c|}
\hline PI & Cluster Codification & $\begin{array}{l}\text { Output Variables } \\
\text { Name/Abbreviation }\end{array}$ & Output Variables Description \\
\hline \multirow{6}{*}{$\begin{array}{l}\text { Animal Performances } \\
\text { (AP) }\end{array}$} & - & Slaughter weight & Slaughter weight \\
\hline & - & ADG & Average daily gain during the finishing period \\
\hline & - & FCR & Feed conversion ratio (ADG/feed intake (DM)) \\
\hline & & Carcass weight & Carcass weight \\
\hline & CP1 & $\mathrm{pH}$ & Ultimate $\mathrm{pH}$ at $24 \mathrm{~h}$ post mortem \\
\hline & $\mathrm{CP} 2$ & Conformation & Carcass conformation \\
\hline \multirow[t]{6}{*}{ Carcass properties $(\mathrm{CP})$} & $\mathrm{CP} 3$ & $\mathrm{~h}^{*} \mathrm{~L}^{*}$ & $\begin{array}{l}\text { Aggregation of hue }\left(h^{*}\right) \text {, luminosity }\left(L^{*}\right) \text { of carcass lean, and } \\
\text { expert evaluation of carcass muscle color }\end{array}$ \\
\hline & $\mathrm{CP} 4$ & Fat development & $\begin{array}{l}\text { Aggregation of several fat tissues (in the fifth quarter, carcass } \\
\text { fat, etc.) }\end{array}$ \\
\hline & CP5 & Fat proportion & $\begin{array}{l}\text { Fat percentage relative to the other components of the carcass } \\
\text { (bone and muscle), aggregate with intermuscular and } \\
\text { intramuscular fat score }\end{array}$ \\
\hline & CP6 & $a^{*} b^{*} c^{*}$ & $a^{*}, b^{*}$, and chroma $\left(C^{*}\right)$ of carcass lean \\
\hline & - & Lipid content & Lipid content \\
\hline & NQ1 & Long FA & Long-chain fatty acid amount and proportion \\
\hline \multirow{7}{*}{$\begin{array}{l}\text { Nutritional Quality of } \\
\text { meat (NQ) }\end{array}$} & NQ2 & C16:0/C18:0 & $\mathrm{C} 16: 0 / \mathrm{C} 18: 0$ ratio \\
\hline & NQ3 & $n-6 / n-3$ & $n-6 / n-3$ ratio \\
\hline & NQ4 & PUFA/MUFA & Polyunsaturated fatty acids/Monounsaturated fatty acids ratio \\
\hline & NQ5 & CLA & Conjugated linoleic acids \\
\hline & NQ6 & Trans FA & Trans fatty acids \\
\hline & - & Tenderness & Tenderness \\
\hline & - & Juiciness & Juiciness \\
\hline \multirow{5}{*}{$\begin{array}{l}\text { Organoleptic Quality } \\
\text { (OQ) }\end{array}$} & OQ1 & Flavor intensity & Flavor intensity \\
\hline & OQ2 & Bitter flavor & Bitter flavor \\
\hline & OQ3 & Rancid fish & Flavors rancid and fish flavors \\
\hline & OQ4 & Fatty vs metal & Fatty versus metallic flavors \\
\hline & OQ5 & Blood acid flavors & Blood acid flavors \\
\hline
\end{tabular}

ADG: average daily gain, FCR: feed conversion ration per pen.

\subsection{Choice and Quality of the Prediction Models}

A synthesis of the 24 models' quality is represented in Figure 1. Random forest was chosen most of the time (18 green intervals) before ridge regression (five red intervals) and the linear regression (one blue interval). Regarding the accuracy of the models, the adjusted $R^{2}\left(\operatorname{adj} R^{2}\right)$ values were higher than 0.8 in most of the prediction models. However, some models were characterized by low or very low adjR $R^{2}$ values, especially $\mathrm{M}_{\mathrm{ADG}}, \mathrm{M}_{\mathrm{pH}}, \mathrm{M}_{\mathrm{CLA}}$, and $\mathrm{M}_{\text {juiciness, }}$ which denote unreliable models.

The correction of the adjusted $R^{2}$ (cor_adj $R^{2}$ ) enabled taking the overfitting of the models into account, and thus estimating the true accuracy of the model on unknown data. For example, the cor_adj $R^{2}$ of the $\mathrm{M}_{\mathrm{FCR}}$ model was only around 0.33 when the adj $\mathrm{R}^{2}$ was higher than 0.9 . Similarly, the $\mathrm{M}_{a^{*} b^{*} C^{*}}$ and $\mathrm{M}_{\text {long FA }}$ appeared to be less accurate when considering their cor_adj $\mathrm{R}^{2}(0.35$ and 0.38 , 
respectively) compared to their adj $R^{2}$ ( 0.95 and 0.90 , respectively). It is interesting to notice that the models with high overfitting were all random forest models.

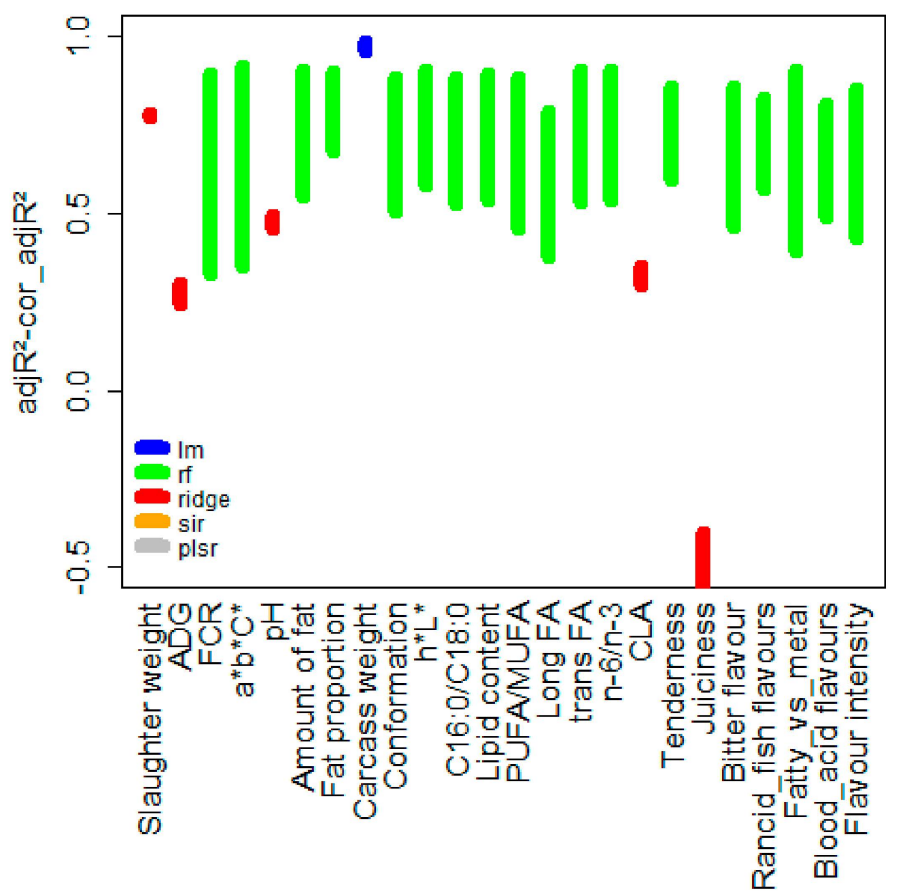

Figure 1. Quality of the 24 prediction models based on the adjusted coefficient of determination calculated twice, represented by vertical segments. The upper (respectively lower) limit of the interval corresponds to the adjusted $R^{2}$ (calculated on the training data) (respectively corrected adjusted $R^{2}$ estimate with a bootstrap approach [23]). The color indicates the model selected from the five competing regression models $(\mathrm{lm}=$ linear model, $\mathrm{rf}=$ random forest, ridge, $\mathrm{sir}=$ slice inverse regression, plsr $=$ partial least square regression).

\subsection{Examination of Models Behavior}

Some of the 24 multivariate regression models that were built were analyzed in this section. The aim of this analysis was to show the main relations between the variables to compare and discuss them further with the current knowledge (Section 4.2.). All the relations are summarized in Figure 2 by the sensitivity index $(\mathrm{Si})$ of every dependent variable into each model. Only the selected variables with the modvarsel method were used to build the model and thus have a corresponding square on the row of the model. It would be too long to describe all the results in Figure 2 one by one, but to take an example, the $\mathrm{M}_{\mathrm{FCR}}$ is mainly influenced by the $\mathrm{pH}(\mathrm{Si}=0.20)$, the conformation $(\mathrm{Si}=0.20)$, and the CLA $(\mathrm{Si}=0.22)$. The rest of the independent variables seem to be not strongly linked to the feed efficiency.

The second method that was used to describe the models' behavior gave complementary

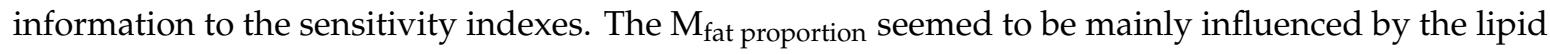
content $(\mathrm{Si}=0.90)$, but the graphical approach also showed that the ADG significantly influenced the model predictions (Figure 2a), even though the sensitivity index was low $(\mathrm{Si}=0.05)$. As observed in Figure 2a, a low growth rate was associated with a high portion of fat and a high amount of intramuscular and intermuscular fat deposits. This example highlighted a contradiction between the two methods, which will be discussed further (Section 4.1.). 


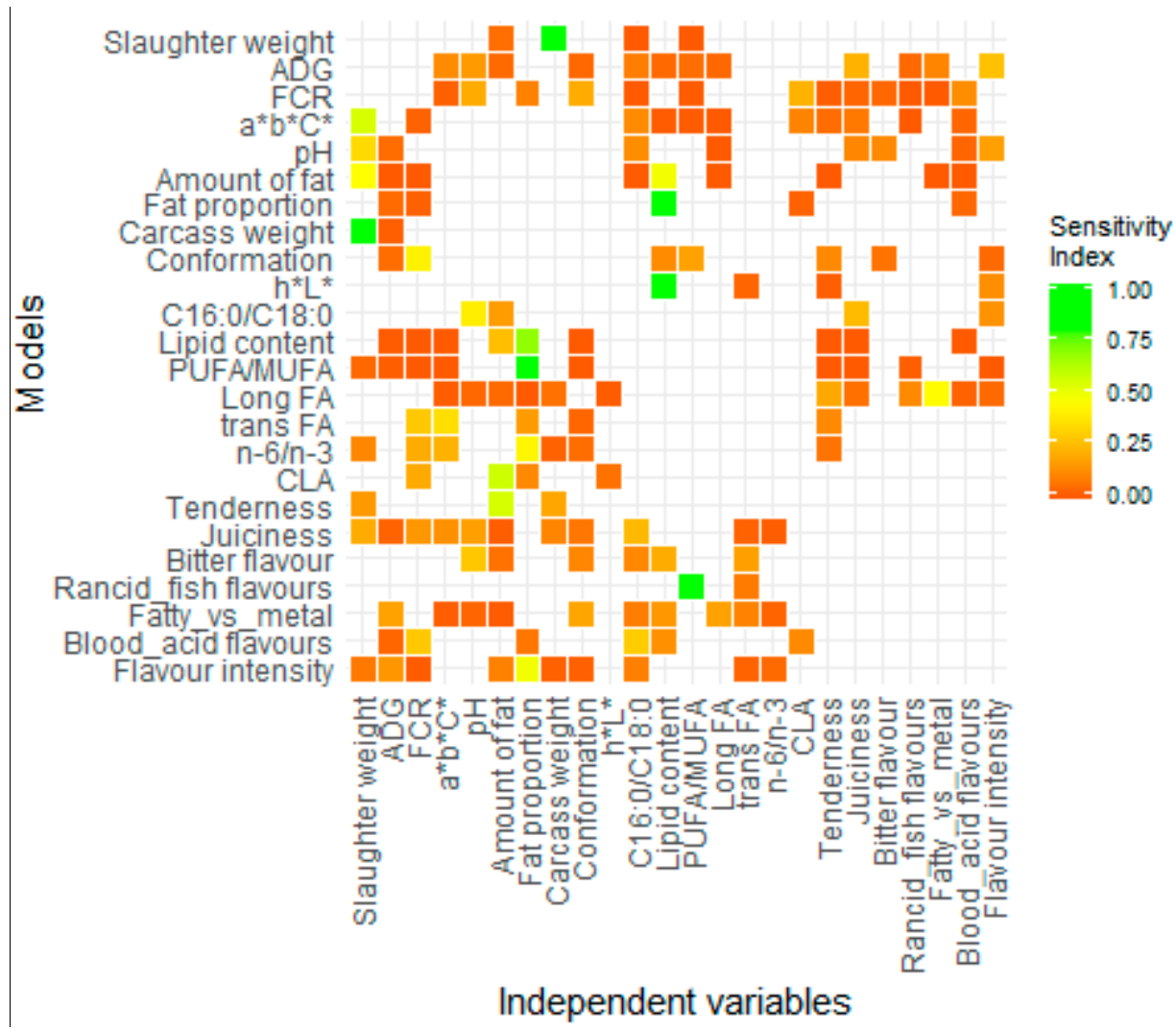

Figure 2. Heat map of the sensitivity index for each variable used (column) in each model (row). Green indicates values that are higher in the sensitivity index. If there is no square, the variable was not used in the corresponding model.

The graphical approach was also a tool to describe the shape of the variations of the prediction. $\mathrm{M}_{\text {PUFA/MUFA }}$ was quite exclusively influenced by fat proportion $(\mathrm{Si}=0.86$ ), even if nine other variables were selected as predictors in model construction. However, it was only thanks to the graphical approach that the relation appeared to be clearly negative. Combining the previous information, it was possible to conclude that a thin carcass was characterized by a higher portion of PUFA (relatively to MUFA) than fatter carcasses. Nevertheless, this relation seemed to not be linear in the model (Figure 2b).

Curious variations were sometimes observed. The $\mathrm{M}_{n-6 / n-3}$ was built with seven independent variables, including the FCR $(\mathrm{Si}=0.20)$ and the fat proportion $(\mathrm{Si}=0.42)$, which were the most influential. The $n-6 / n-3$ prediction was low for the intermediate values of FCR and fat proportions, and higher when the variables were getting close to the edges of the values tested (Figure 2c).

$\mathrm{M}_{\text {Tenderness }}$ appeared to be mainly linked to the amount of fat $(\mathrm{Si}=0.55)$ and the weight of the animal $(\mathrm{Si}=0.15)$ or of its carcass $(\mathrm{Si}=0.19)$. The sum of all the independent variables was not exactly equal to one. This observation was almost always true for all the model analyses, and will therefore be discussed further (Section 4.1.). The influence of fat development was not very clear in Figure 2d. The highest tenderness seems to be reached for intermediate fat development. The tenderness seemed to be also very low when the animals were very fat.

Although some of the models were difficult to interpret with biological certitude, there were

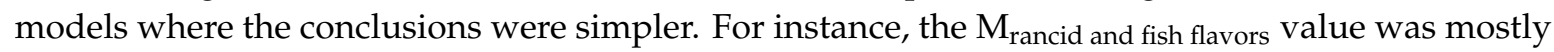
affected by the PUFA/MUFA ( $\mathrm{Si}=0.81$ ). In Figure $2 \mathrm{e}$, it is clearly shown that after reaching a certain proportion of PUFA (relatively to MUFA), the level of unwanted flavors dramatically increased.

Likewise, the $\mathrm{M}_{\text {flavor intensity }}$ was highly impacted by fat proportion $(\mathrm{Si}=0.48)$ with a high intensity when the measure was high (Figure 2f). Therefore, the flavor intensity was easily linked to the 
intermuscular and the intramuscular fat, which partly composed the cluster and thus the linear combination calculated from it.

\subsection{Global Relation between Nutritional and Organoleptic Quality}

The Organoleptic Quality (OQ) and the Nutritional Quality (NQ) indexes of the virtual animals (points) are displayed in Figure 3, and overlapped by the 30 real animals (triangles) used to build the models. A slight negative correlation was observed between NQ and OQ $(r=-0.17)$ for the indexes calculated with the virtual animals. The same correlation with the real animals was a little bit higher $(r=-0.25)$, but stayed very low, indicating that these two parameters are only weakly linked. The correlation test indicates that the correlation between the synthetic indexes calculated with the virtual animals was significantly different from zero. This test does not show the strength of the correlation and is highly influenced by the number of observations, as it can be observed with a higher $\mathrm{p}$ value for the real animal, even though the correlation seemed to be stronger.

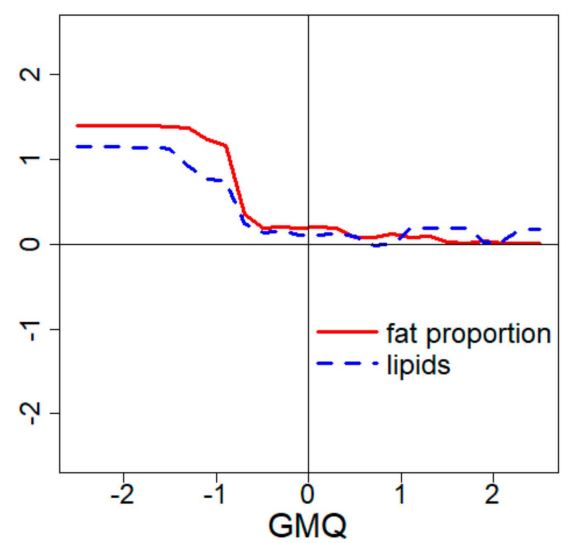

(a)

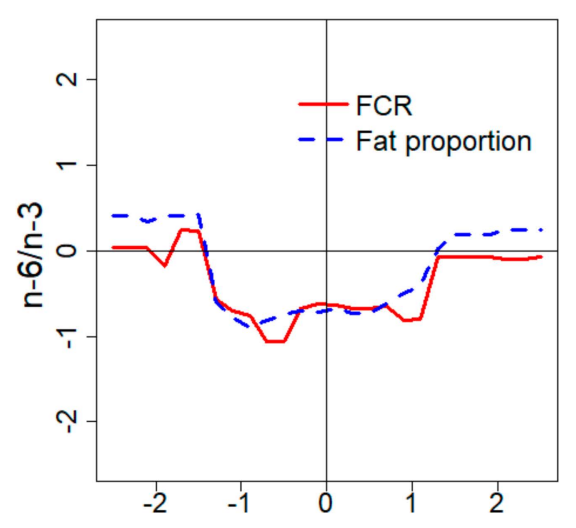

(c)

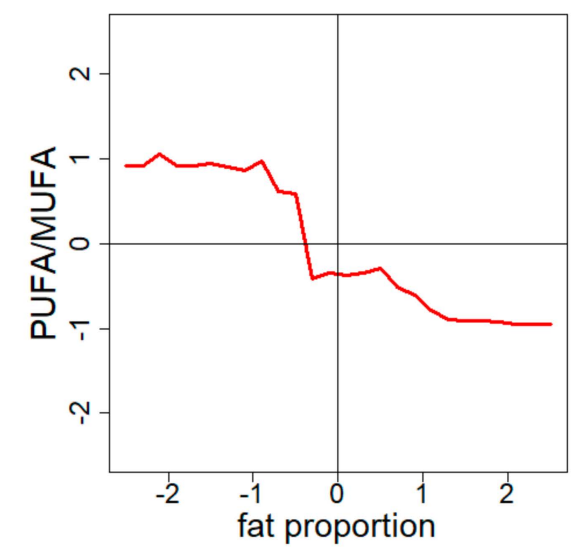

(b)

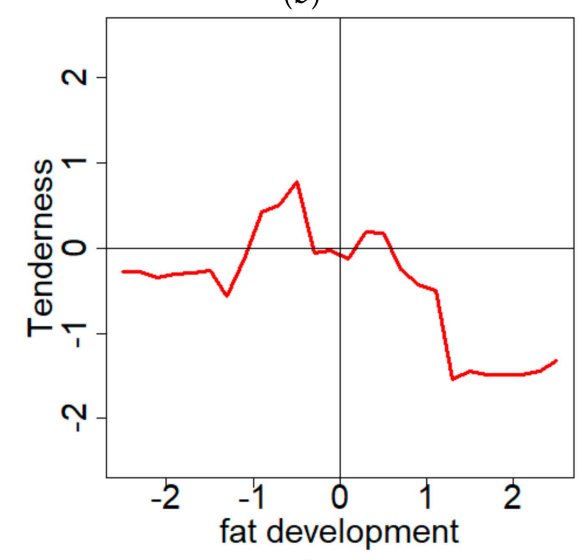

(d)

Figure 3. Cont. 


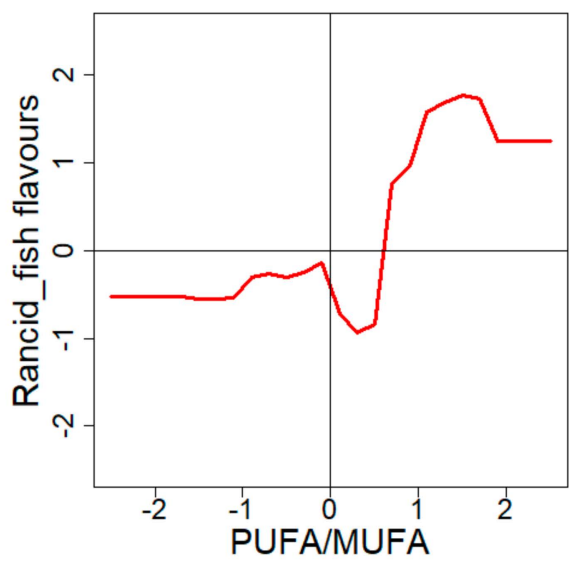

(e)

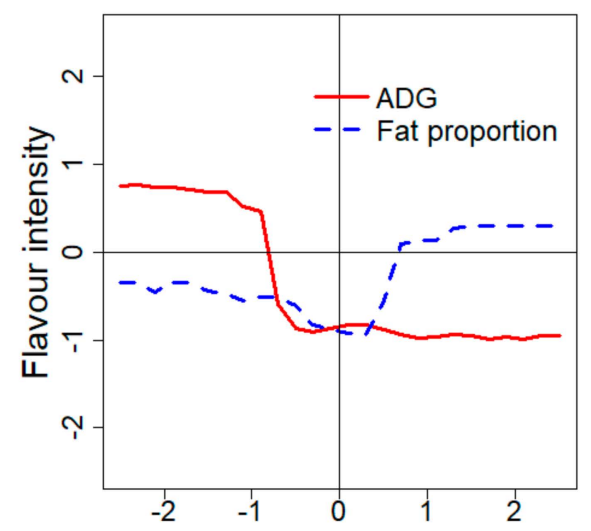

(f)

Figure 3. (a) Prediction of the fat proportion and the lipid content versus the ADG (average daily gain) variations; (b) Prediction of the PUFA/MUFA (polyunsaturated fatty acid/monounsaturated fatty acid)ratio versus the fat proportion variations; (c) Prediction of the $n-6 / n-3$ ratio versus the FCR (feed conversion ratio) and fat proportion variations; (d) Prediction of the tenderness versus the fat development variation; (e) Prediction of the unwanted rancid-fish flavor versus the PUFA/MUFA ratio variations; (f) Prediction of the flavor intensity versus the ADG and the fat proportion variations.

\subsection{Comparison between the Best and the Worst Profile}

Among the virtual animals (Figure 4), the traits of the 30 best (blue points) and worst (red points) animals were compared in Figure 5. Overlapped on the boxplots, three real animals for each category (best and worst) were also selected (black triangles) in Figure 4 and compared with virtual ones in Figure 5 (blue and red triangles). Since they were selected for their nutritional and organoleptic quality, the best animals naturally have better traits regarding these qualities.

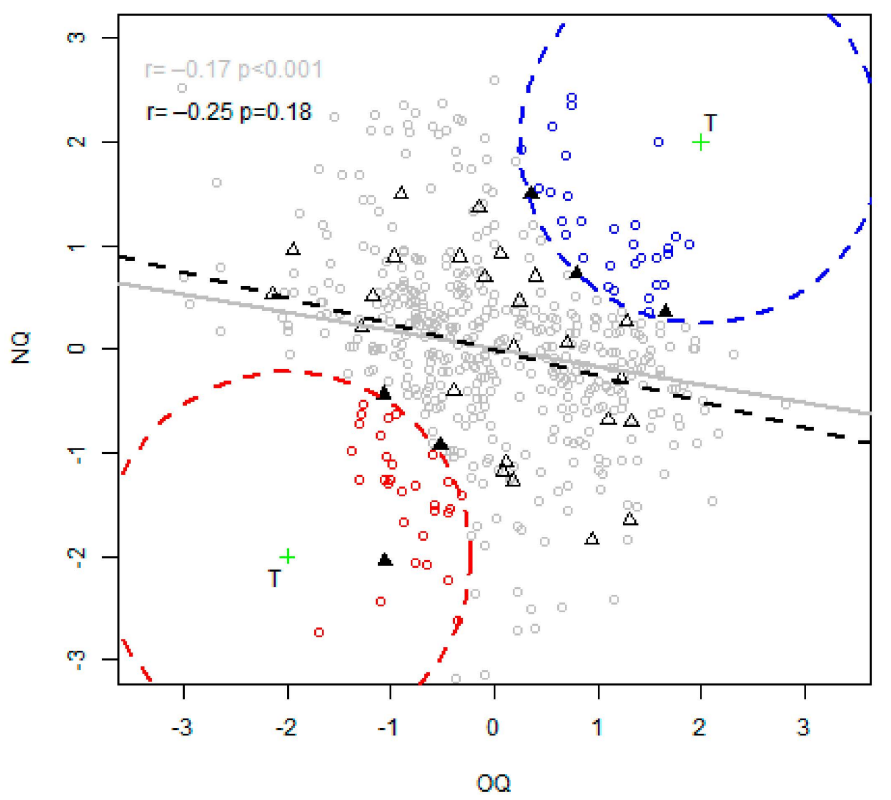

Figure 4. Nutritional and organoleptic indexes of the virtual (points) and real (triangles) animals. The correlation of the virtual (respectively real) animals is given in grey (respectively in black) in the top left corner. Regression (NQ OQ) line for both virtual and real animals is added to visualize the correlation. Two targeted green crosses $\mathrm{T}$ were set to select the closest best (blue) and worst (red) virtual animals (and real animals filled in black for both categories). 




(a)

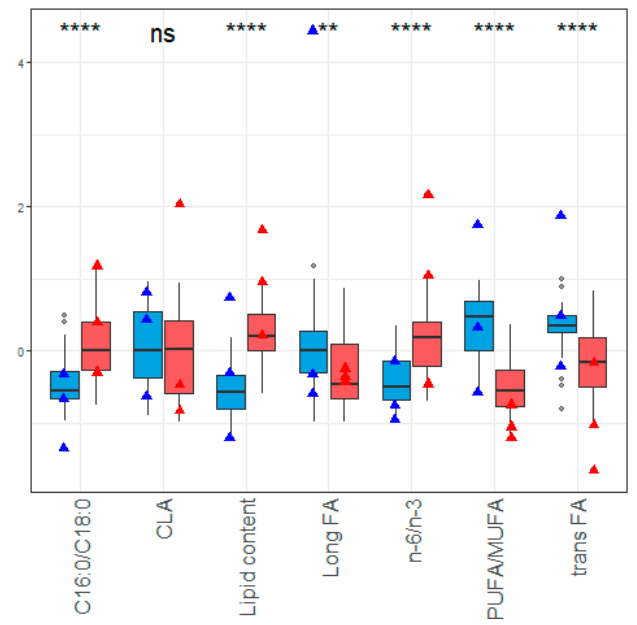

(c)



(b)

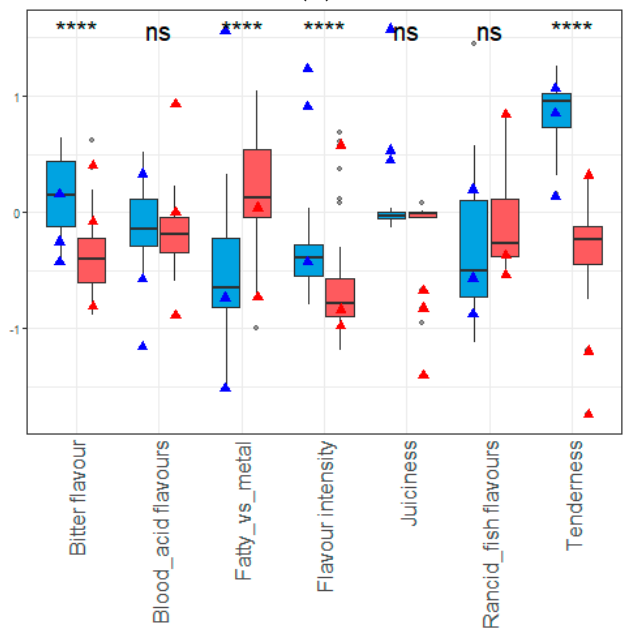

(d)

Figure 5. Comparison (boxplots) of the virtual animals traits between the worst (red) and the best (blue) profiles selected. The three best and worst real animals are added on the boxplots with triangles. For each variable, the result of a Wilcoxon test is provided (ns: no significant, ${ }^{* *}: p$ value $<0.01$, ${ }^{* * *}: p$ value $<0.001, * * * *: p$ value $\left.<0.0001\right)$. (a) animal performances; $(\mathbf{b})$ carcass properties; (c) nutritional quality; (d) organoleptic quality.

Regarding the organoleptic quality (Figure 4d), the best animals had a better tenderness and flavor intensity than the worst animals. Even though the models were useless for the juiciness (predicting only the mean juiciness, because the model does not fit the variation of the juiciness at all), the best real animals (triangles) seemed to have a better juiciness than the worst real animals selected. On the abnormal flavor side, the best animals seemed to be more bitter than the worst animals, but the fatty/metal taste was stronger for the worst animals. No significant difference was reported for the rancid/fish and blood/acid flavor between the two extremes.

Regarding nutritional quality, the best animals had lower lipid content (Figure 5c). Logically, the C16:0 proportion was lower, meaning probably that the SFA content was also lower. In addition, PUFA/MUFA was higher, which also seems logical when the SFA is low. Among the higher proportion of PUFA, the $n-3$ fatty acid seemed to have a higher proportion in comparison to the $n-6$. Associated with higher PUFA proportions, trans fatty acids were also higher. No significant difference between CLA proportions was observed, but the proportion of long fatty acids was higher for the best animals. 
Although not selected for this parameter of interest, the worst animals seemed to have fatter carcasses that were heavier and had conformations (Figure $5 b$ ). Those fatter carcasses seemed to have an impact on the luminescence $\left(L^{*}\right)$ of the meat, but not on the $a^{*} b^{*} C^{*}$ indicator, where no difference was observed. The $\mathrm{pH}$ of the virtual animals seemed higher for the best virtual animals, even though this result was in contradiction with the six real animals selected.

Related to these observations on the carcass traits, the slaughter weight of the best animals was lighter. To produce fatter carcasses, it seems that the worst animals also had a lower feed efficiency (Figure 5a). No difference between the average daily gain was observed even if best real animals tended to be better.

\section{Discussion}

\subsection{Modeling and Analytic Choices}

All the approaches were based on a reliable modeling of the relations between the variables evaluating the parameters of interest. Some of the models were clearly not reliable. The worst case was that of the juiciness, which had very low adjusted $R^{2}$ values, and seemed not able to predict anything other than the juiciness mean (as can be seen in Figure $5 \mathrm{~d}$ ).

The results coming out the modvarsel package will also be discussed, especially regarding the type of model selection. Among the five considered regression models in the modvarsel R package, two model types have never been selected: plsr and sir (see Figure 1). This could be explained by a lack of (linear) structure regarding the variables and the relatively low number of observations (animals) compared to the relatively high number of independent variable candidates. Thus, the dimension reduction techniques were affected and not better than the other competitive fully parametric or non-parametric regression models. Linear regression was selected only once. In contrast, random forest (a purely non-parametric approach) gave a good accuracy in this kind of situation, which explained the high rate of random forest model selected by modvarsel.

Linear regression was selected to predict the carcass weight, which was strongly correlated with the animal's body weight before slaughter. Curiously, the slaughter weight was not fitted by a linear regression model, in which carcass weight would be the main independent variable in return. Indeed, it appears that a higher number of variables was selected by modvarsel to fit the slaughter weight (carcass weight, fat development, C16:0/C18:0 ratio, and PUFA/MUFA ratio) than to fit the carcass weight (slaughter weight and ADG). Some slight correlations between the four variables were observed, such as between carcass weight and fat development $(r=0.67, p$ value $<0.001)$ for instance, which might explain the use of penalized regression to build a more stable model, as aimed by the modvarsel algorithm. The low number of observations $(n=30)$ with influential points could also be the source of instability (high variance of the parameters' estimation) in the linear model fitting slaughter weight.

As it was noticed in the results (Section 3.2.), all 18 random forest models had high overfitting. This is related to the non-parametric nature of the algorithm, which is known to produce high overfitting when the number of observations is low compared to the number of independent variable [29]. For instance, it was interesting to notice that the $M_{n-6 / n-3}$ variations were characterized by a kind of "wave", where the ratio was favorable for intermediate values of FCR and fat proportion. These relations did not have a clear biological explanation. Nevertheless, increasing the size of the training dataset might prevent the overfitting problem, with the robustness of the non-parametric models being based on the law of large numbers.

As noticed in Section 3.3, when analyzing the models, contradictions appeared between the two methods (i.e., the sensitivity indexes (Si) and the graphical approach). For instance, regarding the $\mathrm{M}_{\text {fat proportion }}$ value, the ADG had a low sensitivity index, but was responsible for a significant part of the variations with the graphical method. In general, those contradictions appeared when the number of independent variables into the model was important, and the accuracy of the model was low. When both of these conditions were met, it could lead to difficulties regarding obtaining a 
reliable sensitivity index. Furthermore, the graphical approach was based on the variation of only one independent variable, and the other one was set to the mean (i.e., 0 ). Therefore, interaction phenomena were factored out of the analysis, which could also explain the opposition between both of the methods' results.

\subsection{Outcome from the Holistic Approach}

First, this original approach has shown that there is not a strong antagonism $(r=-0.17)$ between nutritional and organoleptic quality. Moreover, the best profiles selected had very satisfying meat quality regarding the quality based on the initial population of 30 animals. This observation consolidated a previous work [2], where Ellies-Oury et al. indicated that these two parameters were orthogonal to each other and thus linearly independent. These results were obtained in a population of heterogeneous animals, which came from three different breeds (Angus, Limousine, Blonde d'Aquitaine), whereas in the present work, the results were obtained on a homogenous population of Blonde d'Aquitaine females. The lack of a strong linkage between the two parameters of interest (NQ and OQ) means that a trade-off is not fully necessary to maximize NQ and OQ simultaneously.

Going deeper in the best profiles analysis, the thin carcasses with a low proportion of fat seemed to drive to high PUFA and w3 proportions in the meat, as well as a higher intensity of flavor and tender meat. In contrast, the fattest carcasses seemed to produce meat with high lipids content that lacked PUFA and had an imbalanced $n-6 / n-3$ ratio. The models explain these results. In Section 3.2, a negative relation was shown between the fat proportion and the PUFA/MUFA ratio. This result support those from Warren et al. [30] indicating that muscles with higher lipid content have a lower proportion of PUFA compared to MUFA and SFA. These could be explained by a higher de novo synthesis of fatty acid, which was mostly saturated and monounsaturated. In leaner meat, the triglycerides/phospholipids ratio was higher, and it is well known that PUFA mainly esterified on phospholipids [31].

In the literature, studies have shown a positive relation between fat and tenderness [32]. However, the model built in this study was different. As noticed in Figure $2 \mathrm{~d}$, the tenderness optimum is reached when the fat development is between -1 and 0 (which means that the animal is close to the mean or lower by one standard deviation), and the worst tenderness predicted was obtained with an upper fat development that was one standard deviation over the mean. This result was also observed in the best and worst profiles. The contradiction between this model and the literature cannot be explained by a low model quality, because the accuracy of the $M_{\text {tenderness }}$ is quite satisfying (adj $R^{2}=0.85$ and cor_adj $R^{2}=0.60$ ). However, the model was fit on a specific population of 30 Blonde d'Aquitaine heifers. This breed is well known to produce very lean meat in comparison to the other suckling breeds [33], which could explain the different relationship between this fat indicator and the tenderness of the meat.

As previously shown, the best animals had higher PUFA/MUFA in the meat. However, high PUFA content can also lead to the risk of unwanted flavor (e.g., the fish flavor indicated in Figure 2e). This effect seems to be related to PUFA oxidation [5]. Nevertheless, the higher level of PUFA in the best profile meat did not cause this kind of abnormal flavor.

Finally, these results confirmed that meat with higher intramuscular and intermuscular fat increases the flavor intensity [4], indicating that intramuscular fat is a precursor of many aromatic compounds formed, notably, during cooking processes.

\subsection{Limits and Perspectives of the Trade-Off Method}

Generating virtual observations is unusual in the animal research field, and might raise interrogations and doubts regarding the results for the reader. However, there are no statistical aberrations, because this study did not try to show the impact of one factor (the diet effect for instance) on the beef performances or meat qualities or the strength of relation between two variables. All the probabilistic tests that were performed in this paper (the Wilcoxon test of comparison between the best and worst profiles traits) should not be interpreted literally; they only demonstrate that with the 
relation modeled in this study, the best profiles are significantly different than the worst ones regarding various traits.

Aside from this innovative approach, the trade-off method seemed to be highly sensitive to the weighting granted for each variable by the experts. For instance, tenderness (whose weighting is significant) was the highest among the best profiles (and lowest among the worst profiles). Then, the result of optimizing was clearly dependent on the expertise provided for the relative importance of each variable evaluating the parameters of interest. Therefore, the choice of variable weights has to be carried out carefully and wisely to manage the trade-offs as efficiently as possible.

The weighting dependence can also be related to the method used to aggregate the variables, considering its numerous disadvantages. The linear combination calculated here to aggregate the variables led to compensation between them. For instance, a high proportion of PUFA would compensate for a high trans fatty acid proportion. No threshold was taken into account as a way to prefer a more balanced animal compared to an animal performing well on only a few indicators. More complex methods exist to resolve these problems such as outranking methods, but suffer from less clarity and are difficult to assess [34]. In addition, the weight-related techniques need variables varying in the same scale and the same direction. In the case of some of them, such as the carcass weight, the optimum value is not a maximum or a minimum weight, but rather a homogeneous weight distributed around a target value.

\section{Conclusions}

The present paper has exposed a very innovative approach to assess the trade-off between parameters of interest in the beef cattle industry. It showed that there is no antagonism between organoleptic quality and nutritional quality. The modeling approach has also been very interesting to highlight the relation between the variables and show that they are interconnected, and not only by two-by-two relations. This knowledge should be taken into account when designing new product brand or label expectations.

However, the very strong influence of the weight setting and the aggregation method on the results of the trade-off was observed. This should encourage the meat beef industry to clarify their own expectations regarding these two parameters of interest in order to set consensual indicators with associated hierarchy to measure the organoleptic and nutritional quality.

Moreover, the significance of these results is only relevant in the particular context of the data in terms of the animals' breed, age, diets, fattening duration, muscle, etc. Thus, the extrapolation of the present results has to be done with caution.

Author Contributions: Methodology, A.C.; formal analysis, C.A., M.-P.E.-O., B.P., J.S., M.C.; data curation, J.N., C.D.; writing — original draft preparation, A.C.; writing—review and editing, C.A., M.-P.E.-O., G.C.-H., B.P., D.D., D.G.; visualization, A.C.; supervision, M.-P.E.-O., B.P., J.S., M.C., D.D., D.G., J.N.

Funding: This research used data which were funded by National agency of research (Agence Nationale de la Recherche, ANR) under the "National program for research in human alimentation and nutrition", project “ANR-06-PNRA-018-03".

Acknowledgments: We would like to thank the technician and administrative staff of the experimental farm of Mauron, the French Livestsock Institute, and of the National Institute of Agricultural Research, which contributed to this work with material and time support. We thank all of the people involved in this project for their assistance in data collection, the management and slaughtering of animals, and muscle sampling. We especially thank Daniel Le Pichon (Brittany Regional Chamber of Agriculture), Didier Bastien, Jérôme Normand, Aude Bertout (French Livestock Institute), Dominique Bauchart, Denys Durand and Mylène Delosière (INRA UMRH, Theix) for the collection and provision of data.

Conflicts of Interest: The authors declare no conflict of interest. 


\section{Appendix A}

Table A1. Variables in the initial dataset with the clustering assignment and the associated coefficient of correlation between the variables and the synthetic index (calculated as the first component of the principal analysis component (PCA) with all the variables in the cluster).

\begin{tabular}{|c|c|c|c|}
\hline Variable & Precision and Units & Cluster Codification & $\begin{array}{l}\text { Correlation with the } \\
\text { Cluster Synthetic Index }\end{array}$ \\
\hline Slaughter weight & Slaughter day weight & - & - \\
\hline ADG & Average daily gain ( $\mathrm{kg} /$ day) during the fattening period (100 days) & - & - \\
\hline FCR & Feed conversion ratio (DM intake/ADG) & - & - \\
\hline Carcass weight & Carcass weight $(\mathrm{kg})$ & $\mathrm{CP} 1$ & -0.96 \\
\hline Conformation & EUROP conformation (from $1(\mathrm{P}-)$ to $15(\mathrm{E}+)$ ) & $\mathrm{CP} 2$ & 1 \\
\hline Body fat score & Body fat score at slaughter (from 1 to 5 ) & $\mathrm{CP} 3$ & -0.74 \\
\hline Pelvis fat & $(\mathrm{kg})^{\circ}$ & $\mathrm{CP} 4$ & 0.79 \\
\hline Kidney fat & (kg) & $\mathrm{CP} 4$ & 0.92 \\
\hline Trimming fat & $(\mathrm{kg})$ & $\mathrm{CP} 4$ & 0.84 \\
\hline Total fat & $(\mathrm{kg})$ & $\mathrm{CP} 4$ & 0.99 \\
\hline Eliminated fat & (kg) & $\mathrm{CP} 4$ & 0.98 \\
\hline Intramuscular fat score & Score from 3 (no trace of fat) to 12 (extremely fat) & CP5 & -0.75 \\
\hline Intermuscular fat score & Score from 0 (without intermuscular fat) to 5 (high intermuscular fat) & CP5 & -0.87 \\
\hline $\mathrm{pH}$ & $\mathrm{pH}$ & $\mathrm{CP} 1$ & 0.81 \\
\hline Meat color score & Score from 1 (very light) to 4 (very red) & $\mathrm{CP} 3$ & 0.74 \\
\hline$L^{*}$ & from black (0) to white (100) of the CIE $L^{*} a^{*} b^{*}$ coordinates system & $\mathrm{CP} 3$ & -0.81 \\
\hline$a^{*}$ & from green $(-)$ to red $(+)$ of the CIE $L^{*} a^{*} b^{*}$ coordinates system & CP6 & 0.99 \\
\hline$b^{*}$ & from blue $(-)$ to yellow $(+)$ of the CIE $L^{*} a^{*} b^{*}$ coordinates system & CP6 & 0.98 \\
\hline$C^{*}$ & The chroma of the CIE $L^{*} C^{*} h^{*}$ coordinates system & CP6 & 1 \\
\hline$h^{*}$ & The hue angle of the CIE $L^{*} C^{*} h^{*}$ coordinates system & $\mathrm{CP} 3$ & -0.85 \\
\hline Muscle proportion & Muscle proportion into the carcass & CP5 & 0.91 \\
\hline Fat proportion & Fat proportion into the carcass & CP5 & -0.95 \\
\hline Bone proportion & Bone proportion into the carcass & $\mathrm{CP} 1$ & 0.97 \\
\hline Lipid content & Lipid content into LT muscle & - & - \\
\hline $\mathrm{C} 16: 0$ & $(\% /$ total FA) & NQ3 & -0.88 \\
\hline C18:0 & (\%/total FA) & NQ2 & 0.95 \\
\hline SFA & (\%/total FA) & NQ3 & -0.86 \\
\hline C18:1 cis 9 & (\%/total FA) & NQ4 & -0.94 \\
\hline MUFA cis & Sum of all MUFAcis (\%/total FA) & NQ4 & -0.93 \\
\hline $\mathrm{C} 18: 1 \operatorname{tr} 9$ & $(\% /$ total FA) & NQ5 & 0.61 \\
\hline $\mathrm{C} 18: 1 \operatorname{tr} 10$ & (\%/total FA) & NQ6 & 0.98 \\
\hline $\mathrm{C} 18: 1 \operatorname{tr} 11$ & (\%/total FA) & NQ5 & 0.92 \\
\hline MUFA trans & Sum of all MUFA trans (\%/total FA) & NQ6 & 0.98 \\
\hline Total MUFA & Sum of all MUFA (\%/total FA) & NQ4 & -0.92 \\
\hline LA & Linoleic acid C18:2 $n-6$ en (\%/total FA) & NQ4 & 0.95 \\
\hline $\mathrm{C} 20: 4 n-6$ & C20:4 n-6 (\%/total FA) & NQ4 & 0.80 \\
\hline Total $n-6$ & Sum of all PUFA $n-6(\% /$ total FA) & NQ4 & 0.97 \\
\hline ALA & Linolenic acid C18:3 n-3 (\%/total FA) & NQ3 & 0.92 \\
\hline EPA & $\mathrm{C} 14: 0(\% /$ total FA) & NQ4 & 0.93 \\
\hline DPA & C14:0 (\%/total FA) & NQ4 & 0.89 \\
\hline Total $n-3$ LC & Sum of all long-chain FA $n-3(\% /$ total FA) & NQ4 & 0.91 \\
\hline Total $n-3$ & Sum of all FA $n-3(\% /$ total FA) & NQ3 & 0.90 \\
\hline LC FA content & Content of all the long-chain FA & NQ1 & 0.98 \\
\hline LC FA prop & Sum of all the long chain FA (\%/total FA) & NQ1 & 0.98 \\
\hline CLA & Conjugated linoleic acid C18:2 9cis 11trans (\%/total FA) & NQ5 & 0.97 \\
\hline total CLA & Sum of all the conjugated FA (\%/total FA) & NQ5 & 0.96 \\
\hline Total PUFA & Sum of PUFA (\%/total FA) & $\mathrm{NQ} 4$ & 0.94 \\
\hline$n-6 / n-3$ & $n-6$ PUFA/n-3 PUFA ratio (\%/total FA) & NQ3 & -0.89 \\
\hline LA/ALA & C18:2 n-6/C18:3n-3 ratio (\%/total FA) & NQ3 & -0.87 \\
\hline PUFA /SFA & PUFA/SFA ratio (\%/total FA) & NQ4 & 0.93 \\
\hline C16:0/C18:0 & $\mathrm{C} 16: 0 / \mathrm{C} 18: 0$ ratio $(\% /$ total FA) & NQ2 & -0.95 \\
\hline Tenderness intensity & Score from 1 (very hard) to 100 (very tender) & - & - \\
\hline Juiciness intensity & Score from 1 (very dry) to 100 (very juicy) & - & - \\
\hline Flavor intensity & Score from 1 (low intensity) to 100 (high intensity) & OQ1 & -0.82 \\
\hline Sweet & Score from 1 (not sweet) to 100 (very sweet) & OQ1 & -0.82 \\
\hline Acid & Score from 1 (not acid) to 100 (very acid) & OQ5 & -0.85 \\
\hline Bitter & Score from 1 (no bitter) to 100 (very bitter) & OQ2 & 1 \\
\hline Metallic taste & Score from 1 (low metallic taste) to 100 (strong metallic taste) & $\mathrm{OQ} 4$ & 0.80 \\
\hline Rancid taste & Score from 1 (low rancid taste) to 100 (strong rancid taste) & OQ3 & 0.88 \\
\hline Fat taste & Score from 1 (low metallic fat) to 100 (strong fat taste) & $\mathrm{OQ} 4$ & -0.80 \\
\hline Fish taste & Score from 1 (low fish taste) to 100 (strong fish taste) & OQ3 & 0.88 \\
\hline Blood taste & Score from 1 (low blood taste) to 100 (strong blood taste) & OQ5 & -0.85 \\
\hline
\end{tabular}

$\mathrm{CP}_{\mathrm{i}}$ : carcass property cluster $\mathrm{i} ; \mathrm{NQ}_{\mathrm{i}}$ : nutritional quality cluster $\mathrm{i}$; $\mathrm{OQ}_{\mathrm{i}}$ : organoleptic quality cluster $\mathrm{i}$. 


\section{Appendix B}

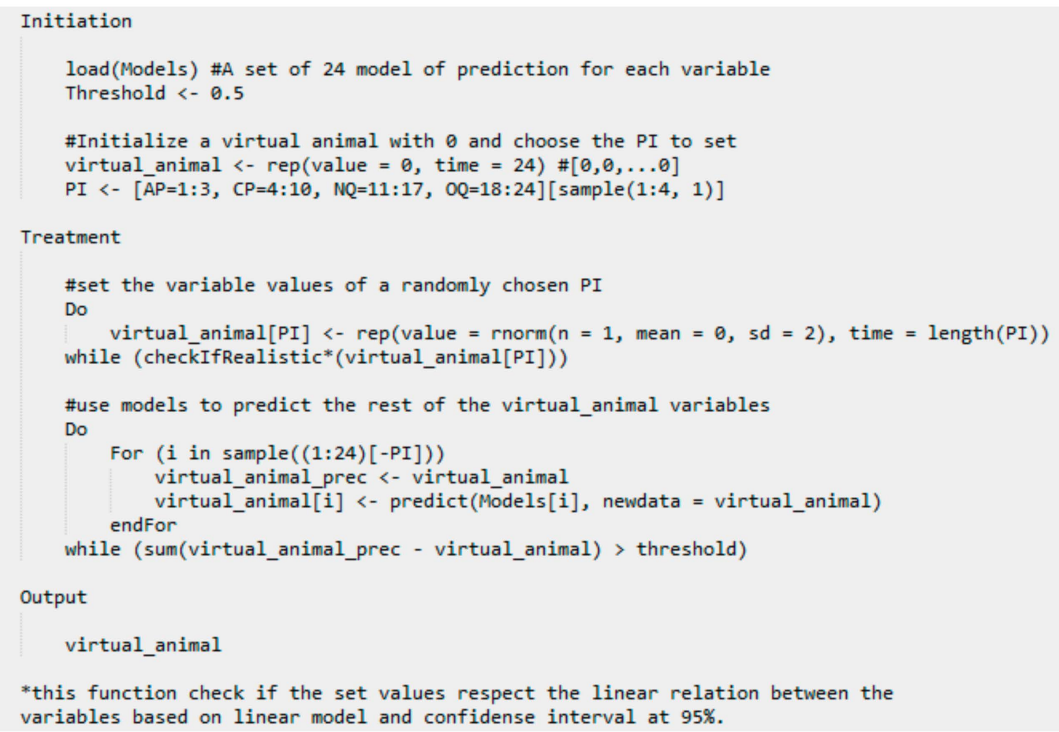

Figure A1. Algorithm to generate a virtual animal. The pseudo code was inspired from the R code.

\section{References}

1. FranceAgriMer. Les Filières Animales Terrestres et Aquatiques Bilan 2013 Perspectives 2014; FranceAgriMer: Paris, France, 2014.

2. Ellies-Oury, M.P.; Cantalapiedra-Hijar, G.; Durand, D.; Gruffat, D.; Listrat, A.; Micol, D.; Ortigues-Marty, I.; Hocquette, J.F.; Chavent, M.; Saracco, J. An innovative approach combining animal performances, nutritional value and sensory quality of meat. Meat Sci. 2016, 122, 163-172. [CrossRef] [PubMed]

3. Jeremiah, L.E.; Dugan, M.E.R.; Aalhus, J.L.; Gibson, L.L. Assessment of the relationship between chemical components and palatability of major beef muscles and muscle groups. Meat Sci. 2003, 65, 1013-1019. [CrossRef]

4. Thompson, J.M. The effects of marbling on flavour and juiciness scores of cooked beef, after adjusting to a constant tenderness. Austral. J. Exp. Agric. 2004, 44, 645-652. [CrossRef]

5. Wood, J.D.; Enser, M.; Fisher, A.V.; Nute, G.R.; Sheard, P.R.; Richardson, R.I.; Hughes, S.I.; Whittington, F.M. Fat deposition, fatty acid composition and meat quality: A review. Meat Sci. 2008, 78, 343-358. [CrossRef] [PubMed]

6. Tables Inra. Alimentation des Bovins, Ovins et Caprins. Besoin des Animaux-Valeurs des Aliments; Quae: Versailles, France, 2007.

7. FranceAgriMer. Pesée/Classement/Marquage; Guide Technique et Reglementaire; FranceAgriMer: Paris, France, 2010.

8. Robelin, J.; Geay, Y.; Jailler, R.; Cuylle, G. Estimation de la composition des carcasses de jeunes bovins à partir de la composition d'un morceau monocostal prélevé au niveau de la 11e côte. I.-Composition anatomique de la carcasse. Ann. Zootech. 1975, 24, 391-402. [CrossRef]

9. Wellington, G.H.; Stouffer, J.R. Beef Marbling: Its Estimation and Influence on Tenderness and Juiciness, 941; Cornell University Agricultural Experiment Station: Ithaca, NY, USA, 1959.

10. Hunt, M.C.; Acton, J.C.; Benedict, R.C.; Calkins, C.R.; Cornforth, D.P.; Jeremiah, L.E.; Olson, D.G.; Salm, C.P.; Savell, J.W.; Shivas, S.D. Guidelines for Meat Color Evaluation; American Meat Science Association, Kansas State University: Manhattan, KS, USA, 1991; pp. 1-17.

11. McLaren, K. An introduction to instrumental shade passing and sorting and a review of recent developments. J. Soc. Dye. Colour. 1976, 92, 317-326. [CrossRef]

12. Habeanu, M.; Thomas, A.; Bispo, E.; Gobert, M.; Gruffat, D.; Durand, D.; Bauchart, D. Extruded linseed and rapeseed both influenced fatty acid composition of total lipids and their polar and neutral fractions in longissimus thoracis and semitendinosus muscles of finishing Normand cows. Meat Sci. 2014, 96, 99-107. [CrossRef] 
13. Folch, J.; Lees, M.; Stanley, G.H.S. A simple method for the isolation and purification of total lipides from animal tissues. J. Biol. Chem. 1957, 226, 497-509.

14. Bauchart, D.; Gobert, M.; Habeanu, M.; Parafita, E.; Gruffat, D.; Durand, D. Influence des acides gras polyinsaturés $n-3$ et des antioxydants alimentaires sur les acides gras de la viande et la lipoperoxydation chez le bovin en finition. Cah. Nutr. Diététique 2010, 45, 301-309. [CrossRef]

15. Scislowski, V.; Durand, D.; Gruffat, D.; Bauchart, D. Dietary linoleic acid-induced hypercholesterolemia and accumulation of very light HDL in steers. Lipids 2004, 39, 125-133. [CrossRef]

16. Chavent, M.; Kuentz-Simonet, V.; Liquet, B.; Saracco, J. ClustOfVar: An R Package for the Clustering of Variables. J. Stat. Softw. 2012, 50,1-16. [CrossRef]

17. Monteils, V.; Sibra, C.; Ellies-Oury, M.P.; Botreau, R.; de la Torre, A.; Laurent, C. A set of indicators to better characterize beef carcasses at the slaughterhouse level in addition to the EUROP system. Livest. Sci. 2017, 202, 44-51. [CrossRef]

18. Pereira, P.M.C.C.; Vicente, A.F.R.B. Meat nutritional composition and nutritive role in the human diet. Meat Sci. 2013, 93, 586-592. [CrossRef]

19. Williams, C.M. Dietary fatty acids and human health. Ann. Zootech. 2000, 49, 165-180. [CrossRef]

20. Williams, C.M. Nutritional composition of red meat. Nutr. Diet. 2007. [CrossRef]

21. Polkinghorne, R.; Philpott, J.; Gee, A.; Doljanin, A.; Innes, J. Development of a commercial system to apply the Meat Standards Australia grading model to optimise the return on eating quality in a beef supply chain. Austral. J. Exp. Agric. 2008, 48, 1451-1458. [CrossRef]

22. Ellies-Oury, M.P.; Chavent, M.; Conanec, A.; Bonnet, M.; Picard, B.; Saracco, J. A relevant way based on variable importance for biomarkers selection to predict meat tenderness. Sci. Rep. 2019. under review.

23. Harrell, F.; Lee, K.; Mark, D. Multivariable prognostic models: issues in developing models, evaluating assumptions and adequacy, and measuring and reducing errors. Stat. Med. 1996, 15, 361-387. [CrossRef]

24. Sobol, I. Global sensitivity indices for nonlinear mathematical models and their Monte Carlo estimates. Math. Comput. Simul. 2001, 55, 271-280. [CrossRef]

25. Iooss, B.; Janon, A.; Pujol, G. Sensitivity: Global Sensitivity Analysis of Model Outputs. R Package Version 1.15.2. Available online: https://CRAN.R-project.org/package=sensitivity (accessed on 6 June 2019).

26. Yang, X.J.; Albrecht, E.; Ender, K.; Zhao, R.Q.; Wegner, J. Computer image analysis of intramuscular adipocytes and marbling in the longissimus muscle of cattle. J. Anim. Sci. 2006, 84, 3251-3258. [CrossRef]

27. Mancini, R.A.; Hunt, M. Current research in meat color. Meat Sci. 2005, 71, 100-121. [CrossRef]

28. ANSES. Actualisation des Apports Nutritionnels Conseillés Pour les Acides Gras; 2006-SA-0359; ANC AG; ANSES: Maisons-Alfort, France, 2006.

29. Breiman, L. Random forests. Mach. Learn. 2001, 45, 5-32. [CrossRef]

30. Warren, H.E.; Scollan, N.D.; Enser, M.; Hughes, S.I.; Richardson, R.I.; Wood, J.D. Effects of breed and a concentrate or grass silage diet on beef quality in cattle of 3 ages. I: Animal performance, carcass quality and muscle fatty acid composition. Meat Sci. 2008, 78, 256-269. [CrossRef] [PubMed]

31. De Smet, S.; Raes, K.; Demeyer, D. Meat fatty acid composition as affected by fatness and genetic factors: A review. Anim. Res. 2004, 53, 81-98. [CrossRef]

32. Bonny, S.P.F.; Hocquette, J.-F.; Pethick, D.W.; Farmer, L.J.; Legrand, I.; Wierzbicki, J.; Allen, P.; Polkinghorne, R.J.; Gardner, G.E. The variation in the eating quality of beef from different sexes and breed classes cannot be completely explained by carcass measurements. Animal 2016, 10, 987-995. [CrossRef]

33. Maniaval, O. Une Nouvelle Utilisation Zootechnique de L'échographie: Estimation de L'état Corporel des Bovins; Application sur Quarante Blondes D'aquitaine en Période D'engraissement. Ph.D. Thesis, Ecole Nationale Vétérinaire de Toulouse-ENVT, Toulouse, France, 2008.

34. Roy, B. The outranking approach and the foundations of ELECTRE methods. In Readings in Multiple Criteria Decision Aid; Springer: London, UK, 1990; pp. 155-183. ISBN 978-3-642-75935-2.

(C) 2019 by the authors. Licensee MDPI, Basel, Switzerland. This article is an open access article distributed under the terms and conditions of the Creative Commons Attribution (CC BY) license (http://creativecommons.org/licenses/by/4.0/). 